Article

\title{
Enhanced Production of a Novel Cyclic Hexapeptide Antibiotic (NW-G01) by Streptomyces alboflavus 313 Using Response Surface Methodology
}

\author{
Zhengyan Guo ${ }^{1,2, *}$, Ling Shen ${ }^{3}$, Zhiqin $\mathrm{Ji}^{1,4,5}$ and Wenjun $\mathrm{Wu}^{1,4,5, *}$
}

1 State Key Laboratory of Crop Stress Biology in Arid Areas, Northwest A \& F University, Yangling 712100, China; E-Mail: jizhiqin@nwsuaf.edu.cn

2 Anhui provincial laboratory of Agro-Food safety, Resources \& Environment College, Anhui Agricultural University, Hefei 230036, China

3 School of Life Sciences, Anhui Agricultural University, Hefei 230036, China; E-Mail: shenling@ahau.edu.cn

4 Shaanxi Province Key Laboratory Research \& Development on Botanical Pesticide, Northwest A \& F University, Yangling 712100, China

5 Key Laboratory of Plant Protection Resources and Pest Integrated Management, Ministry of Education, College of Plant Protection, Northwest A \& F University, Yangling 712100, China

* Authors to whom correspondence should be addressed; E-Mails: gzhengyan@hotmail.com (Z.G.); wuwenjun@nwsuaf.edu.cn (W.W.); Tel.: +86-29-87092191 (Z.G.); Fax: +86-29-87093987 (Z.G.); Tel./Fax: +86-29-87093987 (W.W.).

Received: 6 January 2012; in revised form: 16 April 2012 / Accepted: 17 April 2012 /

Published: 24 April 2012

\begin{abstract}
NW-G01, produced by Streptomyces alboflavus 313, is a novel cyclic hexapeptide antibiotic with many potential applications, including antimicrobial activity and antitumor agents. This study developed a system for optimizing medium components in order to enhance NW-G01 production. In this study, Plackett-Burman design (PBD) was used to find the key ingredients of medium components, and then response surface methodology (RSM) was implemented to determine their optimal concentrations. The results of PBD revealed that the crucial ingredients related to the production of NW-G01 were $\left(\mathrm{NH}_{4}\right)_{2} \mathrm{SO}_{4}$, peptone and $\mathrm{CaCO}_{3}$. A prediction model has been built in the experiments of central composite design and response surface methodology, and its validation has been further verified. The optimal medium composition was determined $(\mathrm{g} / \mathrm{L})$ : corn starch 15 , glucose 15, peptone 3.80, $\left(\mathrm{NH}_{4}\right)_{2} \mathrm{SO}_{4} 0.06, \mathrm{NaCl} 1.5, \mathrm{CaCO}_{3} 1.30, \mathrm{MgSO}_{4} \cdot 7 \mathrm{H}_{2} \mathrm{O} 0.015$,
\end{abstract}


$\mathrm{K}_{2} \mathrm{HPO}_{4} \cdot 3 \mathrm{H}_{2} \mathrm{O} \quad 0.015, \mathrm{MnCl}_{2} \cdot 4 \mathrm{H}_{2} \mathrm{O} \quad 0.015, \mathrm{FeSO}_{4} \cdot 7 \mathrm{H}_{2} \mathrm{O} \quad 0.015$, and $\mathrm{ZnSO}_{4} \cdot 7 \mathrm{H}_{2} \mathrm{O} 0.015$. Compared with NW-G01 production $(5.707 \mathrm{mg} / \mathrm{L})$ in non-optimized fermentation medium, the production of NW-G01 (15.564 $\mathrm{mg} / \mathrm{L})$ in optimized fermentation medium had a 2.73-fold increase.

Keywords: NW-G01; medium optimization; Streptomyces alboflavus 313; Plackett-Burman design; response surface methodology

\section{Introduction}

Agricultural antibiotic produced by different species of actinomyces is a biological product from a natural resource. Agricultural antibiotics have been attracting growing interest with the development of environmentally friendly and safe integrated crop management. In our ongoing screening for new bioactive microbial compounds, a novel hexapeptide antibiotic NW-G01 (Figure 1) was obtained by Streptomyces alboflavus 313 which is isolated from a soil sample collected from Shaanxi province of China. Absolute structure was determined using a combination of single crystal X-ray diffraction and Marfey's method finally. The antibiotic incorporated one molecule of valine, $N$-methyl-alanine, chlorinated pyrroloindoline derivative, and three molecules of piperazic acids [1,2]. Interestingly, NW-G01 exhibited strong antibacterial activity against several species of gram-positive bacteria, such as Bacillus subtilis, Bacillus cereus, and Staphyloccocus aureus [3]. In addition, it had strong in vitro fungistatic activity against some plant pathogen, such as Sclerotinia sclerotiorum, Botrytis cinerea, Coniothyrium diplodiella and Exserohlum turcium [4]. These consequences imply that NW-G01 has the potential to be developed into anti-infection agents or agro-fungicides.

Figure 1. The molecular structure of Novel Cyclic Hexapeptide Antibiotic (NW-G01).

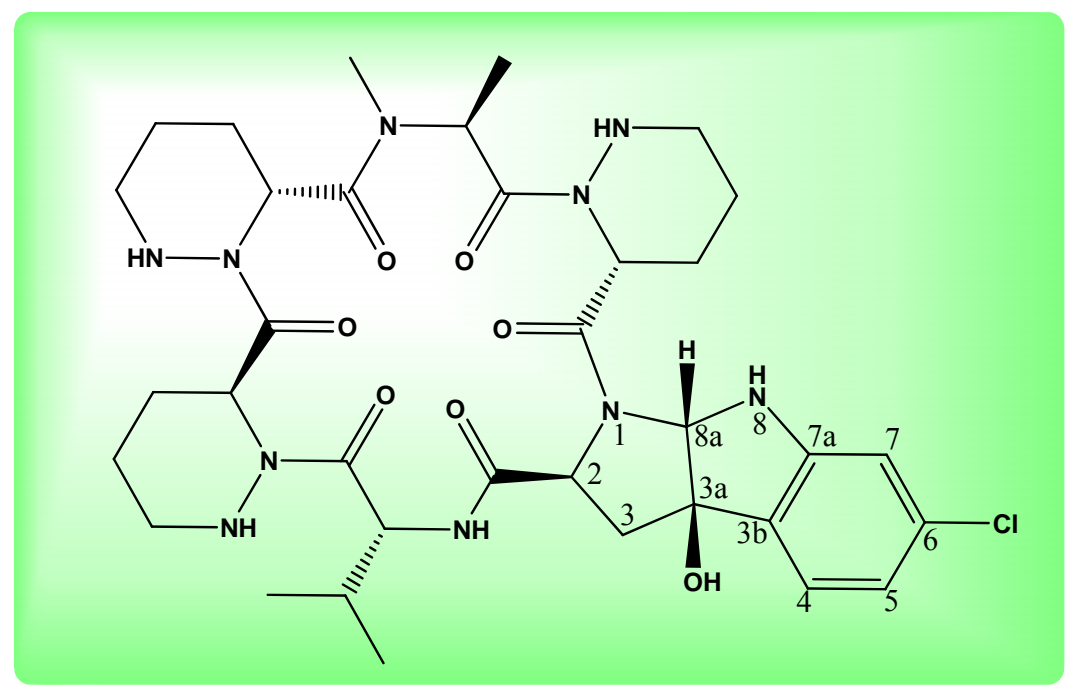

An appropriate fermentation medium is one of the crucial factors in the antibiotic industry, because the medium composition could significantly affect secondary metabolic yield from microorganisms [5]. The conventional method for medium optimization is the "one-factor-at-a-time" approach, which is 
time consuming, labor expensive, and does not take into consideration the interactions between multiple factors involved when a large number of variables have to be investigated. The main advantage of optimizing the parameters by statistical experimental design is to eliminate these limitations of single factor optimization process [6]. Plackett-Burman is widely used in the statistical designs for the selection of the medium components, which can screen the important variables as well as their significance levels [7]. Following this, factorial design and response surface analysis are used to determine the optimum values of the factors studied based on the initial screening. In the present biotechnology study, several researchers have applied these techniques for the optimization of culture conditions, determination of optimal values of processing parameters and feeding rates [8-11]. Furthermore, these techniques also have been successfully applied to the optimization of medium components and cultivation conditions for metabolic production by Streptomyces [12-17] and other microorganisms [18-21]. Response Surface Methodology (RSM) has eased process development and has been of significant use at industrial level, among which central composite design methodology considers the interaction effects among the variables [22].

To the best of our knowledge, the medium requirements for $S$. alboflavus 313 in liquid fermentation have not been demonstrated. Moreover, it is necessary and important to decrease production cost and to enhance productivity. This paper explores the feasibility of production of NW-G01 in liquid fermentation by $S$. alboflavus 313 and its optimization by RSM. Initially, effects of various carbon sources, nitrogen sources and inorganic salts were investigated by a Plackett-Burman design, and subsequently by RSM. Finally, the production of NW-G01 was validated using the optimized condition.

\section{Results and Discussion}

\subsection{Optimization by Plackett-Burman Design (PBD)}

The importance of the eleven components, corn starch, glucose, $\left(\mathrm{NH}_{4}\right)_{2} \mathrm{SO}_{4}$, peptone, $\mathrm{NaCl}, \mathrm{CaCO}_{3}$, $\mathrm{MgSO}_{4} \cdot 7 \mathrm{H}_{2} \mathrm{O}, \mathrm{K}_{2} \mathrm{HPO}_{4} \cdot 3 \mathrm{H}_{2} \mathrm{O}, \mathrm{MnCl}_{2} \cdot 4 \mathrm{H}_{2} \mathrm{O}, \mathrm{FeSO}_{4} \cdot 7 \mathrm{H}_{2} \mathrm{O}$ and $\mathrm{ZnSO}_{4} \cdot 7 \mathrm{H}_{2} \mathrm{O}$ for NW-G01 production was investigated by PBD. The results showed the effects of these components on the response and significant levels in Tables 1 and 2.

According to statistical analysis of the data by Design expert software, the results showed that only $\left(\mathrm{NH}_{4}\right)_{2} \mathrm{SO}_{4}$, peptone and $\mathrm{CaCO}_{3}$ had confidence levels above $95 \%(p<0.05)$ and were considered to influence NW-G01 production significantly. The others had confidence levels below $95 \%$ and hence were considered insignificant. In these results, $R^{2}=0.9285$ indicated that $92.85 \%$ of the variability in the response could be explained in the model.

PBD results indicated that the effect of $\left(\mathrm{NH}_{4}\right)_{2} \mathrm{SO}_{4}$, peptone and $\mathrm{CaCO}_{3}$ were negative. Decreasing the three components concentration might result in higher production of antibiotic NW-G01. Thus, the three variables $\left(\mathrm{NH}_{4}\right)_{2} \mathrm{SO}_{4}\left(x_{3}\right)$, peptone $\left(x_{4}\right)$ and $\mathrm{CaCO}_{3}\left(x_{6}\right)$ were selected and their optimal levels were identified further using response surface methodology. 
Table 1. The Plackett-Burman design for screening variables in NW-G01 production.

\begin{tabular}{|c|c|c|c|c|c|c|c|}
\hline \multirow{2}{*}{ Factors(g/L) } & \multirow{2}{*}{ Code } & \multirow{2}{*}{$\begin{array}{c}\text { Low } \\
\text { Level (-) }\end{array}$} & \multirow{2}{*}{$\begin{array}{c}\text { High } \\
\text { Level (+) }\end{array}$} & \multirow{2}{*}{ Effect } & \multirow{2}{*}{ Coefficient } & \multicolumn{2}{|c|}{ NW-G01 Production } \\
\hline & & & & & & t-Value & $P$-Value \\
\hline Intercept & & & & & 3.18 & 22.73 & $0.0004^{\mathrm{a}}$ \\
\hline Corn starch & $x_{1}$ & 10 & 20 & 0.41 & 0.2 & 1.37 & 0.3046 \\
\hline Glucose & $x_{2}$ & 10 & 20 & 0.84 & 0.42 & 1.90 & 0.1163 \\
\hline$\left(\mathrm{NH}_{4}\right)_{2} \mathrm{SO}_{4}$ & $x_{3}$ & 2 & 4 & -4.83 & -2.41 & 65.93 & $<0.0001^{\mathrm{a}}$ \\
\hline Peptone & $x_{4}$ & 3 & 6 & -1.67 & -0.83 & 7.89 & $0.0262^{\mathrm{a}}$ \\
\hline $\mathrm{NaCl}$ & $x_{5}$ & 1 & 2 & 0.28 & 0.14 & 0.15 & 0.1000 \\
\hline $\mathrm{CaCO}_{3}$ & $x_{6}$ & 1 & 2 & -2.15 & -1.07 & 13.08 & $0.0085^{\mathrm{a}}$ \\
\hline $\mathrm{MgSO}_{4} \cdot 7 \mathrm{H}_{2} \mathrm{O}$ & $x_{7}$ & 0.01 & 0.02 & 0.57 & 0.29 & 1.40 & 0.2341 \\
\hline $\mathrm{K}_{2} \mathrm{HPO}_{4} \cdot 3 \mathrm{H}_{2} \mathrm{O}$ & $x_{8}$ & 0.01 & 0.02 & 1.19 & 0.59 & $4 . .01$ & 0.0854 \\
\hline $\mathrm{MnCl}_{2} \cdot 4 \mathrm{H}_{2} \mathrm{O}$ & $x_{9}$ & 0.01 & 0.02 & -0.31 & -0.16 & -1.12 & 0.4643 \\
\hline $\mathrm{FeSO}_{4} \cdot 7 \mathrm{H}_{2} \mathrm{O}$ & $x_{10}$ & 0.01 & 0.02 & -0.88 & -0.44 & -1.65 & 0.1493 \\
\hline $\mathrm{ZnSO}_{4} \cdot 7 \mathrm{H}_{2} \mathrm{O}$ & $x_{11}$ & 0.01 & 0.02 & -0.57 & -0.28 & -1.68 & 0.1919 \\
\hline
\end{tabular}

Table 2. The Plackett-Burman design variables (in coded levels) with NW-G01 production as response.

\begin{tabular}{|c|c|c|c|c|c|c|c|c|c|c|c|c|}
\hline \multirow{2}{*}{ Run } & \multicolumn{11}{|c|}{ Variable Level } & \multirow{2}{*}{$\begin{array}{c}\text { NW-G01 } \\
\text { (mg/L) }\end{array}$} \\
\hline & $x_{1}$ & $x_{2}$ & $x_{3}$ & $x_{4}$ & $x_{5}$ & $x_{6}$ & $x_{7}$ & $x_{8}$ & $x_{9}$ & $x_{10}$ & $x_{11}$ & \\
\hline 1 & -1 & 1 & -1 & 1 & 1 & -1 & 1 & 1 & 1 & -1 & -1 & 7.64 \\
\hline 2 & -1 & -1 & -1 & 1 & -1 & 1 & 1 & -1 & 1 & 1 & 1 & 1.73 \\
\hline 3 & -1 & 1 & 1 & -1 & 1 & 1 & 1 & -1 & -1 & -1 & 1 & 0.89 \\
\hline 4 & 1 & 1 & -1 & -1 & -1 & 1 & -1 & 1 & 1 & -1 & 1 & 6.15 \\
\hline 5 & 1 & -1 & 1 & 1 & 1 & -1 & -1 & -1 & 1 & -1 & 1 & 0.05 \\
\hline 6 & -1 & -1 & 1 & -1 & 1 & 1 & -1 & 1 & 1 & 1 & -1 & 0.04 \\
\hline 7 & 1 & 1 & -1 & 1 & 1 & 1 & -1 & -1 & -1 & 1 & -1 & 3.57 \\
\hline 8 & 1 & -1 & 1 & 1 & -1 & 1 & 1 & 1 & -1 & -1 & -1 & 0.26 \\
\hline 9 & -1 & 1 & 1 & 1 & -1 & -1 & -1 & 1 & -1 & 1 & 1 & 0.83 \\
\hline 10 & 1 & 1 & 1 & -1 & -1 & -1 & 1 & -1 & 1 & 1 & -1 & 2.54 \\
\hline 11 & -1 & -1 & -1 & -1 & -1 & -1 & -1 & -1 & -1 & -1 & -1 & 6.74 \\
\hline 12 & 1 & -1 & -1 & -1 & 1 & -1 & 1 & 1 & -1 & 1 & 1 & 7.74 \\
\hline
\end{tabular}

\subsection{Optimization by Response Surface Methodology}

RSM using central composite design (CCD) was applied to determine the optimal levels of the three selected variables that affected the production of NW-G01. The respective low and high levels $(\mathrm{g} / \mathrm{L})$ with the coded levels for the factors are defined in Table 3.

The concentrations of the other factors were fixed at zero level as shown in Table 1. Experimental design and results are shown in Table 4.

The experimental results were fitted with the second-order polynomial (Equation (1)):

$$
\begin{aligned}
& Y=13.57-3.46 x_{3}-0.17 x_{4}-2.77 x_{6}-0.75 x_{3} x_{4}- \\
& 0.51 x_{3} x_{6}+1.09 x_{4} x_{6}-1.32 x_{3}{ }^{2}-1.18 x_{4}{ }^{2}+0.70 x_{6}{ }^{2}
\end{aligned}
$$


where $Y$ was the predicted response, $x_{3}, x_{4}$ and $x_{6}$ were coded values of $\left(\mathrm{NH}_{4}\right)_{2} \mathrm{SO}_{4}$, peptone and $\mathrm{CaCO}_{3}$ concentration, respectively.

Table 3. Levels of the factors tested in the central composite design (CCD).

\begin{tabular}{cccccccc}
\hline \multirow{2}{*}{ Variables } & \multirow{2}{*}{ Units } & \multirow{2}{*}{\begin{tabular}{c} 
Symbol \\
\cline { 3 - 8 }
\end{tabular}} & & \multicolumn{6}{c}{ Level } \\
\cline { 4 - 8 } & & Code & $\mathbf{- 1 . 6 8 2}$ & $-\mathbf{1}$ & $\mathbf{0}$ & $\mathbf{1}$ & $\mathbf{1 . 6 8 2}$ \\
\hline $\left.\mathrm{NH}_{4}\right)_{2} \mathrm{SO}_{4}$ & $\mathrm{~g} / \mathrm{L}$ & $x_{3}$ & 0.06 & 0.4 & 0.9 & 1.4 & 1.74 \\
$\mathrm{Peptone}$ & $\mathrm{g} / \mathrm{L}$ & $x_{4}$ & 1.32 & 2 & 3 & 4 & 4.68 \\
$\mathrm{CaCO}_{3}$ & $\mathrm{~g} / \mathrm{L}$ & $x_{6}$ & 0.33 & 0.6 & 1 & 1.4 & 1.67 \\
\hline
\end{tabular}

Table 4. Central composite design matrix for the experimental design and predicted responses for NW-G01 production.

\begin{tabular}{cccccc}
\hline \multirow{2}{*}{ Run } & & Coded Level & \multicolumn{3}{c}{ NW-G01 Production(mg/L) } \\
\cline { 2 - 6 } & $\boldsymbol{x}_{\mathbf{3}}$ & $\boldsymbol{x}_{\mathbf{4}}$ & $\boldsymbol{x}_{\mathbf{6}}$ & Observed & Predicted \\
\hline 1 & 0 & 0 & 0 & 13.33 & 13.57 \\
2 & -1 & -1 & 1 & 11.61 & 11.29 \\
3 & 1.682 & 0 & 0 & 3.54 & 4.02 \\
4 & 0 & -1.682 & 0 & 10.15 & 10.50 \\
5 & 0 & 0 & -1.682 & 19.94 & 20.22 \\
6 & 0 & 0 & 0 & 13.25 & 13.57 \\
7 & -1.682 & 0 & 0 & 15.46 & 15.65 \\
8 & 0 & 0 & 0 & 13.47 & 13.57 \\
9 & 0 & 0 & 0 & 13.72 & 13.57 \\
10 & 1 & -1 & 1 & 5.07 & 4.85 \\
11 & 0 & 0 & 0 & 13.96 & 13.57 \\
12 & 1 & 1 & -1 & 9.74 & 9.58 \\
13 & -1 & 1 & -1 & 17.22 & 14.64 \\
14 & -1 & 1 & 1 & 14.72 & 5.19 \\
15 & 1 & 1 & 1 & 5.62 & 13.60 \\
16 & 1 & -1 & -1 & 13.99 & 16.97 \\
17 & 0 & 1.682 & 0 & 9.62 & 9.93 \\
18 & 0 & 0 & 1.682 & 10.49 & 10.89 \\
19 & -1 & -1 & -1 & 18.04 & 17.99 \\
20 & 0 & 0 & 0 & 13.80 & 13.57 \\
\hline
\end{tabular}

The statistical significance of Equation (1) was checked by $F$-test, and the ANOVA for response surface quadratic model is summarized in Table 5. The model $F$-value of 222.43 implied the model was significant, the $P$-value was also very low $(<0.0001)$ indicating that there was only a $0.01 \%$ chance that a "Model $F$-Value" this large could occur due to noise. The success of the model could be checked by the determination coefficient $R^{2}$, which was calculated to be 0.9850 , indicating that $98.50 \%$ of the variability in the response could be explained by the model. Normally, a regression model, having an $R^{2}$-value higher than 0.9 , was considered as a high correlation [23]. The present $R^{2}$-value, therefore, reflected a very good fit between the observed and predicted responses, and it was considered reasonable to use the regression model to analyze trends of the responses. A lower value of coefficient variation $(\mathrm{CV}=3.33 \%)$ showed the experiments conducted were precise and reliable [24]. 
The Lack of fit $P$-value of 0.1095 implied the "Lack of Fit" is not significant relative to the pure error and no-significant lack of fit indicated the model is good.

The significance of the regression coefficients was tested by a $t$-test. The regression coeffiecients and corresponding $p$-values for the model presented in Table 6. Values of "Prob $>F$ " less than 0.05 indicate that model terms are significant while values greater than 0.1 indicate that the model terms are not significant [25]. Therefore, among the model terms in the present study, $\left(\mathrm{NH}_{4}\right)_{2} \mathrm{SO}_{4}\left(x_{3}\right)$ and $\mathrm{CaCO}_{3}\left(x_{6}\right)$ were very significant with probability of over $99 \%$ while peptone $\left(x_{4}\right)$ was not significant with a probability of over $84 \%$. In Table 6 , the results also indicated that the mutual interaction between $x_{3}$ and $x_{3}, x_{4}$ and $x_{4}, x_{6}$ and $x_{6}, x_{3}$ and $x_{4}, x_{3}$ and $x_{6}, x_{4}$ and $x_{6}$, had a very significant influence on antibiotics NW-G01 production.

Table 5. Analysis of variance (ANOVA) for the second-order polynomial model.

\begin{tabular}{lccccc}
\hline Source & SS & DF & MS & $\boldsymbol{F}$-Value & Prob $>\boldsymbol{F}$ \\
\hline Model & 338.6167 & 9 & 37.6241 & 222.43 & $<0.0001$ \\
Residual & 1.6915 & 10 & 0.1692 & & \\
Lack of Fit & 1.2958 & 5 & 0.2592 & 3.27 & 0.1095 \\
Pure Error & 0.3957 & 5 & 0.0791 & & \\
Cor Total & 340.3083 & 19 & & & \\
\hline
\end{tabular}

SS, sum of squares; DF, Degree of freedom; MS, mean square. $R^{2}=0.9850, R_{\text {adj }}^{2}=0.9706$, $R_{\text {pred }}^{2}=0.9591, \mathrm{CV}=3.33 \%$, PRESS $=10.51$.

Table 6. Regression results of the central composite design.

\begin{tabular}{ccc}
\hline Factor & Coefficient & $\boldsymbol{P}$-Value \\
\hline Intercept & 13.57 & \\
$x_{3}$ & -3.46 & $<0.0001^{\mathrm{a}}$ \\
$x_{4}$ & -0.17 & 0.1617 \\
$x_{6}$ & -2.77 & $<0.0001^{\mathrm{a}}$ \\
$x_{3} x_{4}$ & -0.75 & $0.0004^{\mathrm{a}}$ \\
$x_{3} x_{6}$ & -0.51 & $0.0055^{\mathrm{a}}$ \\
$x_{4} x_{6}$ & 1.09 & $<0.0001^{\mathrm{a}}$ \\
$x_{3}{ }^{2}$ & -1.32 & $<0.0001^{\mathrm{a}}$ \\
$x_{4}{ }^{2}$ & -1.18 & $<0.0001^{\mathrm{a}}$ \\
$x_{6}{ }^{2}$ & 0.70 & $<0.0001^{\mathrm{a}}$ \\
\hline
\end{tabular}

${ }^{\text {a }}$ Statistically significant at $95 \%$ of confidence level.

The final results showed that among the independent factors, $x_{3}\left(\left(\mathrm{NH}_{4}\right)_{2} \mathrm{SO}_{4}\right)$ and $x_{6}\left(\mathrm{CaCO}_{3}\right)$ had significant effects on antibiotic NW-G01 production and the negative coefficient of them showed a linear effect to decrease antibiotics NW-G01 production. The quadratic term of the three factors and the interaction between $x_{3}\left(\left(\mathrm{NH}_{4}\right)_{2} \mathrm{SO}_{4}\right), x_{4}$ (peptone) and $x_{6}\left(\mathrm{CaCO}_{3}\right)$ also had a significant effect.

The $3 \mathrm{D}$ response surface curves were then plotted to explain the interactions of medium components and the optimum concentration of each component required for the NW-G01 production (Figures 2-4). Each figure presents the effect of two factors while the other factor was held at zero level. These 3D plots and their respective contour plots provided a visual interpretation of the interaction between two factors and facilitate the location of optimum experimental conditions. 
Figure 2. Response surface curve for NW-G01 production by Streptomyces alboflavus 313 as a function of $\left(\mathrm{NH}_{4}\right)_{2} \mathrm{SO}_{4}$ and peptone concentrations, when $\mathrm{CaCO}_{3}$ concentration was maintained at $1.00 \mathrm{~g} / \mathrm{L}$.

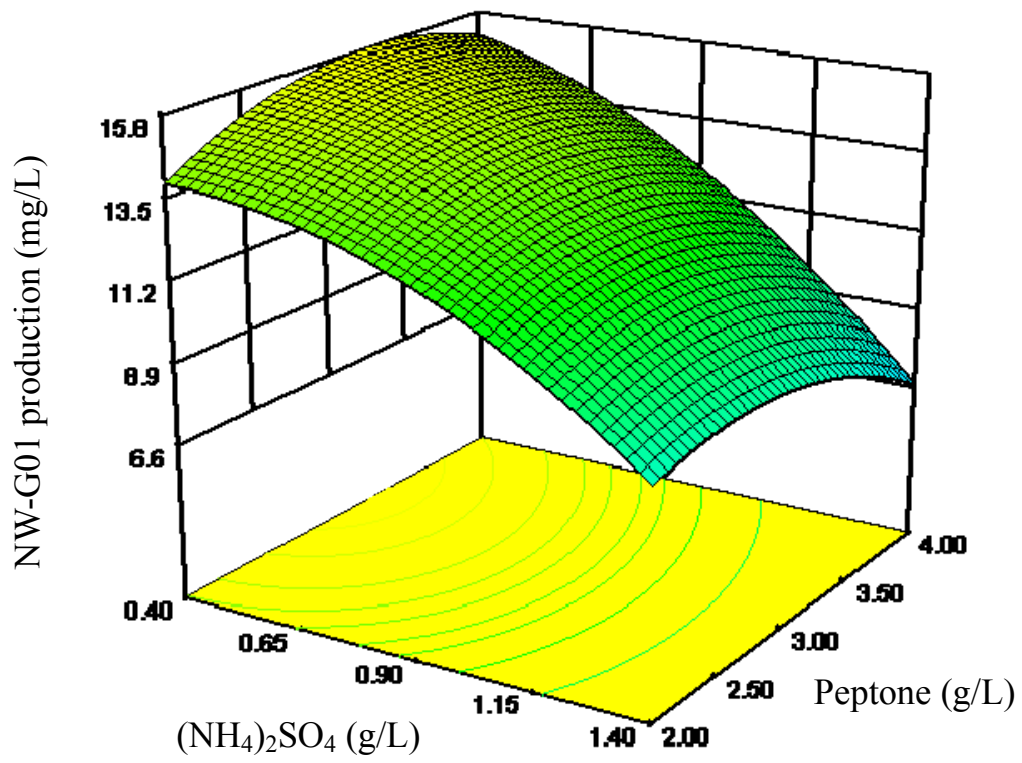

Figure 3. Response surface curve for NW-G01 production by Streptomyces alboflavus 313 as a function of $\left(\mathrm{NH}_{4}\right)_{2} \mathrm{SO}_{4}$ and $\mathrm{CaCO}_{3}$ concentrations, when peptone concentration was maintained at $3.00 \mathrm{~g} / \mathrm{L}$.

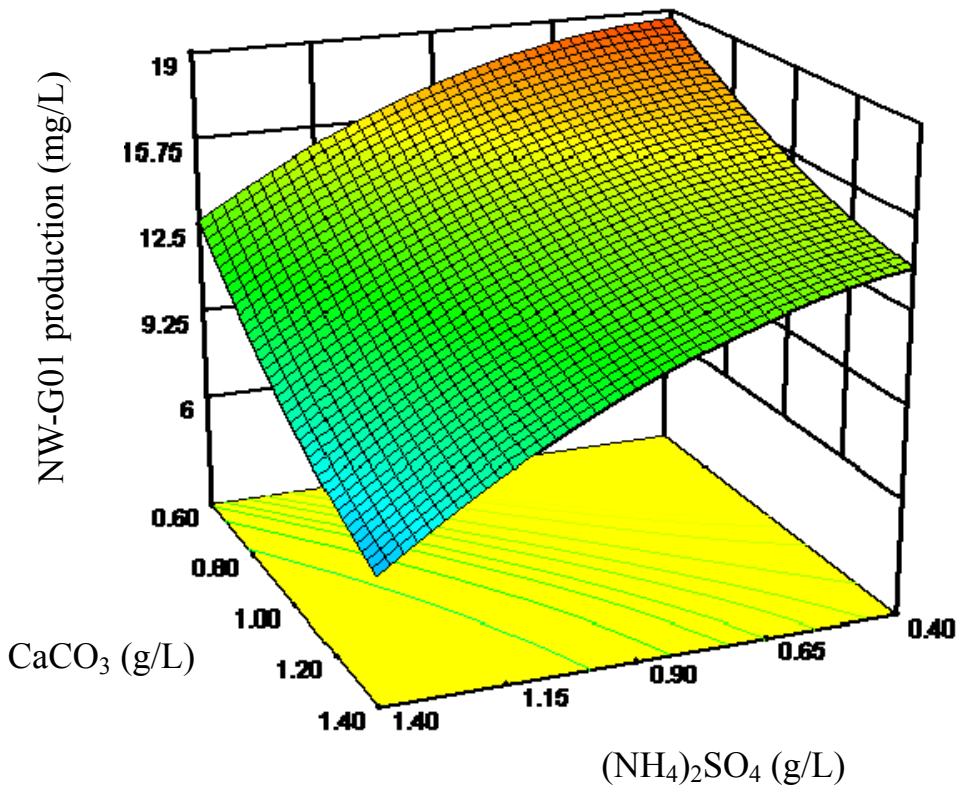


Figure 4. Response surface curve for NW-G01 production by Streptomyces alboflavus 313 as a function of peptone and $\mathrm{CaCO}_{3}$ concentrations, when $\left(\mathrm{NH}_{4}\right)_{2} \mathrm{SO}_{4}$ concentration was maintained at $0.90 \mathrm{~g} / \mathrm{L}$.

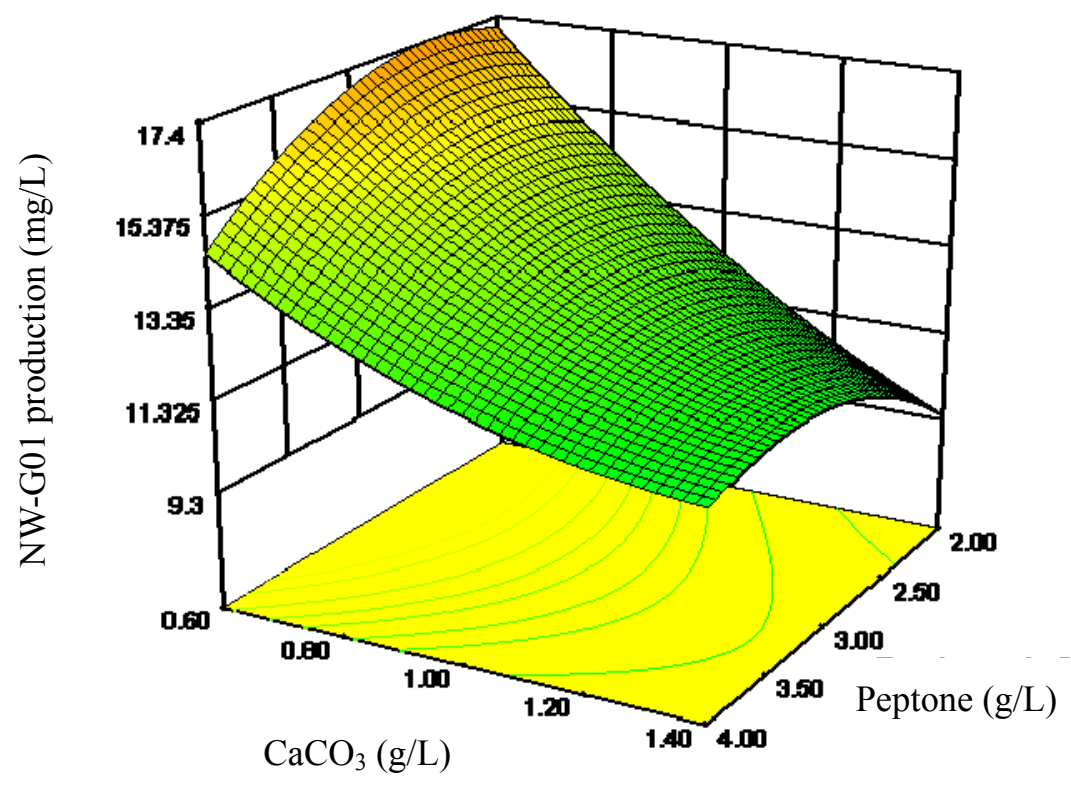

\subsection{Validation of the Optimized Condition}

On the basis of medium optimization, the quadratic model predicted that the maximum production of NW-G01 was $15.387 \mathrm{mg} / \mathrm{L}$, when the model predicted the optimal values of test factors in the coded units were $x_{3}=-1.68, x_{4}=0.80$ and $x_{6}=0.74$, which were $0.06 \mathrm{~g} / \mathrm{L}\left(\mathrm{NH}_{4}\right)_{2} \mathrm{SO}_{4}, 3.80 \mathrm{~g} / \mathrm{L}$ peptone and $1.30 \mathrm{~g} / \mathrm{L} \mathrm{CaCO}_{3}$, respectively. To verify the predicted results, validation experiments in shake flasks were performed in triplicate testes. Under the optimized medium, the observed experimental value of average NW-G01 concentration was $15.564 \mathrm{mg} / \mathrm{L}$, suggesting that experimental and predicted values $(15.387 \mathrm{mg} / \mathrm{L})$ of NW-G01 yield were in good agreement. The concentration was $5.707 \mathrm{mg} / \mathrm{L}$ in non-optimized medium, 2.73-fold increase had been obtained, while the growth of the strain in the two media was comparable. This result therefore corroborated the predicted values and the effectiveness of the model, indicating that the optimized medium favors the production of NW-G01.

\section{Experimental Section}

\subsection{Microorganism}

The strain 313 was isolated from the soil samples from the northeast of China, which was identified as S. alboflavus 313 based on morphological, physiological characteristics and analysis of the 16S rDNA sequence. The culture was maintained at $4{ }^{\circ} \mathrm{C}$ on modified Humic acid-Vitamins (HV) agar slants. The strain was stored in glycerol suspension $(30 \%, \mathrm{v} / \mathrm{v})$ at $-20^{\circ} \mathrm{C}$.

\subsection{Medium and Culture Conditions}

Fermentation was performed in two stages: seed growth and antibiotics NW-G01 production. For the seed growth stage, medium from a plate culture was inoculated into $100 \mathrm{~mL}$ of seed medium 
(glucose $20 \mathrm{~g} / \mathrm{L}$, peptone $6 \mathrm{~g} / \mathrm{L}, \mathrm{NaCl} 2.5 \mathrm{~g} / \mathrm{L}, \mathrm{CaCO}_{3} 1 \mathrm{~g} / \mathrm{L} . \mathrm{pH} 7.0$ ) in a 500-mL Erlenmeyer flask and grown at $28{ }^{\circ} \mathrm{C}$ with $180 \mathrm{rpm}$ on a rotary shaker (ShangHai Fuma Test Equipment Co., Ltd.) for $16 \mathrm{~h}$. Then, $10 \%(\mathrm{v} / \mathrm{v})$ seed cultures were inoculated into $50-\mathrm{mL}$ production medium in a $250-\mathrm{mL}$ Erlenmeyer flask. The strain was incubated at $28{ }^{\circ} \mathrm{C}$ with $180 \mathrm{rpm}$ on a rotary shaker for $108 \mathrm{~h}$. Triplicate experiments were carried out and the mean value was calculated.

In our preliminary experiments, various carbon and nitrogen sources, and inorganic salts were evaluated for the suitability to sustain good NW-G01 production by $S$. alboflavus 313 . The results revealed that the major variable affecting the performance of the medium in terms of NW-G01 yield were corn starch, glucose, peptone, $\left(\mathrm{NH}_{4}\right)_{2} \mathrm{SO}_{4}, \mathrm{NaCl}, \mathrm{CaCO}_{3}, \mathrm{MgSO}_{4} \cdot 7 \mathrm{H}_{2} \mathrm{O}, \mathrm{K}_{2} \mathrm{HPO}_{4} \cdot 3 \mathrm{H}_{2} \mathrm{O}$, $\mathrm{MnCl}_{2} \cdot 4 \mathrm{H}_{2} \mathrm{O}, \mathrm{FeSO}_{4} \cdot 7 \mathrm{H}_{2} \mathrm{O}$, and $\mathrm{ZnSO}_{4} \cdot 7 \mathrm{H}_{2} \mathrm{O}$. Components were chosen for further optimization. The amount of every component was changed in different experimental processes and the $\mathrm{pH}$ of production medium was 7.0.

\subsection{Analytical Method}

After centrifuging the fermentation broth $(3000 \mathrm{rpm}, 10 \mathrm{~min}), 1 \mathrm{~mL}$ supernatants were filtered $(0.45 \mu \mathrm{m})$ and analyzed by high performance liquid chromatography (HPLC, Shimadzu 6AD, Kyoto, Japan) using a Sinochrom ODS-BP $(5 \mu \mathrm{m}, 4.6 \mathrm{~mm} \times 250 \mathrm{~mm})$ reverse phase column, methanol-water $(75 / 25, \mathrm{v} / \mathrm{v})$ as the mobile phase, flow rate of $1.0 \mathrm{~mL} / \mathrm{min}$, monitored by UV detector at $210 \mathrm{~nm}$ [1].

\subsection{Experimental Design and Data Analysis}

\subsubsection{Plackett-Burman Design (PBD)}

PBD was employed for screening the most significant fermentation parameters affecting NW-G01 production with $S$. alboflavus 313. Each independent variable was tested at high and low levels, which are denoted by $(+)$ and $(-)$, respectively. The experimental design with the name, symbol code, and actual levels of the variables is shown in Table 1, whereas Table 2 shows the detail of the design.

\subsubsection{Central Composite Design (CCD) and Response Surface Methodology (RSM)}

Central composite design (CCD) and response surface methodology (RSM) were employed to optimize the three most significant factors $\left(\left(\mathrm{NH}_{4}\right)_{2} \mathrm{SO}_{4}\right.$, peptone, $\left.\mathrm{CaCO}_{3}\right)$ for enhancing NW-G01 production. The three independent variables were studied at five different levels $(-1.682,-1,0,1$, 1.682) (Table 3) and a set of 20 experiments were carried out (Table 4).

The factors were coded according to the following equation:

$$
x_{i}=\frac{\sum\left(X_{i}-X_{0}\right)}{\Delta X}, i=1,2,3, \ldots, k
$$

where $x_{i}$ was the coded independent factor, $X_{i}$ was the real independent factor, $X_{0}$ was the value of $X_{i}$ at the center point and $\Delta X$ was the step change value.

The response variable (antibiotic production) was explained by the following second-order polynomial equation: 


$$
Y=\beta_{0}+\sum \beta_{i} x_{i}+\sum \beta_{i i} x_{i}^{2}+\sum \beta_{i j} x_{i} x_{j}, i=1,2,3, \ldots, k
$$

where $Y$ was the predicted response, $\beta_{0}$ was the intercept, $x_{\mathrm{i}}$ and $x_{\mathrm{j}}$ were the coded independent factors, $\beta_{\mathrm{i}}$ was the linear coefficient, $\beta_{\mathrm{ii}}$ was the quadratic coefficient and $\beta_{\mathrm{ij}}$ was the interaction coefficient.

\subsubsection{Statistical Analysis}

Design Expert Version 7.1 (Stat-Ease Inc.: Minneapolis, MN, USA, 2007) was used for the experimental designs and regression analysis of the experimental data. Statistical analysis of the model was performed to evaluate the analysis of variance (ANOVA). The quality of the polynomial model equation was judged statistically by the coefficient of determination $R^{2}$, and its statistical significance was determined by an $F$-test. The significance of the regression coefficients was tested by a $t$-test.

\subsubsection{Experimental Validation of the Optimized Medium}

In order to validate the optimization of medium composition, three tests were carried out using the optimized condition, to confirm the result from the analysis of the response surface.

\section{Conclusion}

Plackett-Burman design and response surface methodology had been proved to be effective on optimization for enhancing NW-G01 production with $S$. alboflavus 313. The final medium composition optimized was $(\mathrm{g} / \mathrm{L})$ : corn starch 15 , glucose 15 , peptone $3.80,\left(\mathrm{NH}_{4}\right)_{2} \mathrm{SO}_{4} 0.06, \mathrm{NaCl} 1.5$, $\mathrm{CaCO}_{3} 1.30, \mathrm{MgSO}_{4} \cdot 7 \mathrm{H}_{2} \mathrm{O} 0.015, \mathrm{~K}_{2} \mathrm{HPO}_{4} \cdot 3 \mathrm{H}_{2} \mathrm{O} 0.015, \mathrm{MnCl}_{2} \cdot 4 \mathrm{H}_{2} \mathrm{O} 0.015, \mathrm{FeSO}_{4} \cdot 7 \mathrm{H}_{2} \mathrm{O} 0.015$, and $\mathrm{ZnSO}_{4} \cdot 7 \mathrm{H}_{2} \mathrm{O}$ 0.015, which resulted in an overall 2.73-fold increase compared with that using the non-optimized medium. Validation experiments were also carried out to verify the adequacy and the accuracy of the model, and the results showed that the predicted value agreed with the experimental values well. The optimum culture medium obtained in this experiment laid a foundation for further study with large scale batch fermentation in a fermenter for NW-G01 production from S. alboflavus 313.

\section{Acknowledgments}

This study was supported by the grant of The National Key Basic Research Program (973 Program, Project No. 2010CB126100) from Science and Technology Ministry of China and the foundation of National Science Program of China (Project No. 31101468).

\section{References}

1. Guo, Z.Y.; Ji, Z.Q.; Zhang, J.W.; Deng, J.; Shen, L.; Liu, W.; Wu, W.J. NW-G01, a novel cyclic hexapeptide antibiotic, produced by Streptomyces alboflavus 313: II. Structural Elucidation. J. Antibiot. 2010, 63, 231-235.

2. Guo, Z.Y.; Ji, Z.Q.; Zhang, J.W.; Deng, J.; Shen, L.; Liu, W.; Wu, W.J. Corrigendum: NW-G01, a novel cyclic hexapeptide antibiotic, produced by Streptomyces alboflavus 313: II. Structural Elucidation. J. Antibiot. 2010, 63, doi:10.1038/ja.2010.116. 
3. Guo, Z.Y.; Shen, L.; Ji, Z.Q.; Zhang, J.W.; Huang, L.Z.; Wu, W.J. NW-G01, a novel cyclic hexapeptide antibiotic, produced by Streptomyces alboflavus 313: I. Taxonomy, fermentation, isolation, physicochemical properties and antibacterial activities. J. Antibiot. 2009, 62, 201-205.

4. Guo, Z.Y. Studies on Antimicrobial Components from Fermentation Broth of Streptomyces alboflavus 313 (In Chinese). Ph.D. Dissertation, Northwest A \& F University, Yangling, China, 2009.

5. Gao, H.; Liu, M.; Liu, J.; Dai, H.Q.; Zhou, X.L.; Liu, X.Y.; Zhuo, Y.; Zhang, W.Q.; Zhang, L.X. Medium optimization for the production of avermectin B1a by Streptomyces avermitilis 14-12A using response surface methodology. Bioresour. Technol. 2009, 100, 4012-4016.

6. Zhang, C.H.; Ma, Y.J.; Yang, F.X.; Liu, W.; Zhang, Y.D. Optimization of medium composition for butyric acid production by Clostridium thermobutyricum using response surface methodology. Bioresour. Technol. 2009, 100, 4284-4288.

7. Plackett, R.L.; Burman, J.P. The design of optimum multifactorial experiments. Biometrica 1946, 33, 305-325.

8. Kalil, S.J.; Maugeri, F.; Rodrigues, M.I. Response surface analysis and stimulation as a tool for bioprocess design and optimization. Process Biochem. 2000, 35, 539-550.

9. Liu, G.Q.; Wang, X.L. Optimization of critical medium components using response surface methodology for biomass and extracellular polysaccharide production by Agaricus blazei. Appl. Microbiol. Biotechnol. 2007, 74, 78-83.

10. Sunitha, K.; Kim, Y.O.; Lee, J.K.; Oh, T.K. Statistical optimization of seed and induction conditions to enhance phytase production by recombinant Escherichia coli. Biochem. Eng. J. 2010, 5, 51-56.

11. Vohara, A.; Satyanarayana, T. A cost effective molasses medium for enhanced cell bound phytase production by Pichia anomala. J. Appl. Microbiol. 2004, 97, 471-476.

12. Jia, B.; Jin, Z.H.; Mei, L.H. Medium optimization based on statistical methodologies for pristinamycins production by Streptomyces pristinaespiralis. Appl. Biochem. Biotechnol. 2008, $144,133-143$.

13. Niladevi, K.N.; Sukumaran, R.K.; Jacob, N.; Anisha, G.S.; Prema, P. Optimization of lactase production from a novel strain Streptomyces psammoticus using response surface methodology. Microbiol. Res. 2009, 164, 105-113.

14. Suutari, M.; Lignell, U.; Hyvarinen, A.; Nevalainen, A. Media for cultivation of indoor Streptomycetes. J. Microbiol. Methods 2002, 51, 411-416.

15. Tuncer, M.; Kuru, A.; Isikli, M.; Sahin, N.; Celenk, F.G. Optimization of extracellular endoxylanase, endoglucanase and peroxidase production by Streptomyces sp. F2621 isolated in Turkey. J. Appl. Microbiol. 2004, 97, 783-791.

16. Xiong, Z.Q.; Tu, X.R.; Tu, G.Q. Optimization of medium composition for actinomycin X2 production by Streptomyces spp. JAU4234 using response surface methodology. J. Ind. Microbiol. Biotechnol. 2008, 35, 729-734.

17. Yu, J.C.; Liu, Q.; Liu, Q.; Liu, X.D.; Sun, Q.; Yan, J.F.; Qi, X.H.; Fan, S.D. Effect of liquid culture requirements on antifungal antibiotic production by Streptomyces rimosus MY02. Bioresour. Technol. 2008, 99, 2087-2091.

18. Khanna, S.; Srivastava, A.K. Statistical media optimization studies for growth and PHB production by Ralstonia eutropha. Process Biochem. 2005, 40, 2173-2182. 
19. Kim, P.; Kim, J.H.; Oh, D.K. Improvement in cell yield of Methylobacterium sp. reducing the inhibition of medium components for poly- $\beta$-hydroxybutyrate production. World J. Microbiol. Biotechnol. 2003, 19, 357-361.

20. Mu, W.; Chen, C.; Li, X.; Zhang, T. Jiang, B. Optimization of culture medium for the production of phenyllactic acid by Lactobacillus sp. SK007. Bioresour. Technol. 2009, 100, 1366-1370.

21. Yuan, L.L.; Li, Y.Q.; Wang, Y.; Zhang, X.H.; Xu, Y.Q. Optimization of critical medium components using response surface methodology for phenazine-L-carboxylic acid production by Pseudomonas sp. M-18Q. J. Biosci. Bioeng. 2008, 105, 232-237.

22. Han, Y.; Li, Z.Y.; Miao, X.L.; Zhang, F.L. Statistical optimization of medium components to improve the chitinase activity of Streptomyces sp. Da11 associated with the South China Sea sponge Craniella australiensis. Process Biochem. 2008, 43, 1088-1093.

23. Chen, X.C.; Bai, J.X.; Cao, J.M. Medium optimization for the production of cyclic adenosine 3',5'-monophosphate by Microbacterium sp. No. 205 using response surface methodology. Bioresour. Technol. 2009, 100, 919-924.

24. Box, G.E.P.; Hunter, W.G.; Hunter, J.S. Statistics for Experimenters: An Introduction to Design, Data Analysis and Model Building; John Wiley: New York, NY, USA, 1978; pp. 291-334.

25. Li, X.Y.; Liu, Z.Q.; Chi, Z.M. Production of phytase by a marine yeast Kodamaea ohmeri BG3 in an oats medium: Optimization by response surface methodology. Bioresour. Technol. 2008, 99, 6386-6390.

(C) 2012 by the authors; licensee MDPI, Basel, Switzerland. This article is an open access article distributed under the terms and conditions of the Creative Commons Attribution license (http://creativecommons.org/licenses/by/3.0/). 